\title{
Geometric morphometry and molecular analysis clarified the identity of Opius sp. aff. bellus (Hymenoptera, Braconidae), a fruit fly parasitoid in Brazil
}

\author{
CLÁUDIA F. MARINHO, FERNANDO L. CÔNSOLI \& ROBERTO A. ZUCCHI \\ ${ }^{1}$ Departamento de Entomologia e Acarologia, Escola Superior de Agricultura Luiz de Queiroz, Univ de São Paulo, Piracicaba, SP, \\ Brasil.E-mail: cfmarinhoo@gmail.com;fconsoli@usp.br; razucchi@usp.br
}

\begin{abstract}
The aim of this study was to clarify the identity of specimens designated as Opius sp. aff. bellus using geometric morphometry and analysis of the ITS2 region of the ribosomal DNA (rDNA) and region D2 of the 28S rDNA. Opius bellus Gahan is a koinobiont endoparasitoid of fruit fly larvae (Diptera: Tephritidae) exclusively found in the Neotropical region, but widely distributed from Mexico to Argentina. Opius sp. aff. bellus is morphologically similar to Opius bellus but exhibits yellowish, instead of dark-brown, posterior tibiae. Twenty anatomical landmarks on the wings from these two taxa sampled from three Brazilian states were analyzed. Multivariate morphometric analysis showed a large amount of morphological similarity between the specimens, indicating they are the same species. Sequence analysis of the ITS 2 showed that intrapopulation variability was similar to interpopulation variability and that the morphotypes were also highly similar. In addition, the D2 region of the $28 \mathrm{~S}$ rDNA displayed high similarity between sequences. Therefore, based on morphometric and molecular analyses, specimens thought to be Opius sp. aff. bellus actually belong to O. bellus.
\end{abstract}

Key words: Chromatic variations, geographic variation, molecular taxonomy

\section{Introduction}

Opius bellus Gahan is a koinobiont endoparasitoid of fruit fly larvae (Diptera: Tephritidae) exclusively found in the Neotropical region, but widely distributed from Mexico to Argentina (Ovruski et al. 2000). Opius bellus parasitizes several species of Anastrepha (their most common hosts), as well as Ceratitis capitata (Wiedemann), Ragholetis ferruginea Hendel and Ragholetotrypeta pastranai Aczél (Ovruski et al. 2000). Opius bellus has been characterized in a broad consensus due to the color variability reported in the original description (Wharton \& Marsh 1978). In Brazil, there are specimens that are morphologically similar to O. bellus but can be distinguished by their yellowish (light) posterior tibiae instead of dark-brown (dark) tibiae. Specimens with yellowish tibiae have been designated Opius sp. aff. bellus (Leonel Júnior et al. 1996), and this name has since been used in the Brazilian literature.

This study sought to clarify the taxonomic identity of Opius sp. aff. bellus using geometric morphometry and molecular analysis of the ITS2 region of the ribosomal DNA (rDNA) and the 28S rDNA D2 region.

\section{Material and methods}

Specimens were collected by several Brazilian researchers using the traditional procedure for collecting fruit fly parasitoids (e.g., Leonel Júnior et al. 1996). Sampling was not performed regularly, and no association between parasitoids and its hosts was established (Table 1). After identification, portions of the specimens were placed in absolute ethanol and stored at $-80^{\circ} \mathrm{C}$ for subsequent extraction of the genomic DNA. The remaining material was placed in $70 \%$ ethanol and used for morphometric analysis. The name Opius sp. is used in place of Opius sp. aff. bellus throughout the text. 
TABLE 1. Distribution of plants and associated parasitoids in the sampled areas in Brazil.

\begin{tabular}{lll}
\hline Parasitoids & Associated plants & Collection sites (states) \\
\hline O. bellus and Opius $\mathrm{sp}$. & Spondias mombin & Amazonas (AM) \\
O. bellus and Opius sp. & Spondias mombin & Amapá (AP) \\
O. bellus and Opius $\mathrm{sp}$. & Psidium cattleianum & Santa Catarina (SC) \\
O. bellus & Psidium cattleianum & Rio Grande do Sul (RS) \\
O. bellus and Opius $\mathrm{sp}$. & - & Rio Grande do Norte (RN) \\
O. bellus and Opius $\mathrm{sp}$. & Coffea arabica & Rio de Janeiro (RJ) \\
O. bellus & Spondias purpurea & Tocantins (TO) \\
\hline
\end{tabular}

Geometric morphometry. Samples of Opius bellus (dark-brown posterior tibiae) and Opius sp. (yellowish posterior tibiae) from the northern (states of Amazonas and Amapá) and the northeastern (state of Rio Grande do Norte) regions of Brazil were studied by analyzing the wings of 201 specimens, being 107 specimens of $O$. bellus and 94 of Opius sp. (Table 2). The left wing of each specimen was removed and mounted in a drop of ethanol onto a microscope slide, and covered with a cover slip, and immediately measured. Images were obtained and digitized using the image-capture system Motic Image Plus $2.0^{\circledR}$ coupled to a light microscope Nikon Eclipse E200 ${ }^{\boxplus}$. Digital images of the wings of all specimens were used to mark 20 fixed homologous anatomical landmarks defined by intersections of the wing veins and of veins with wing margin. These landmarks were recorded using the TpsDig version 1.40 software package (Rohlf 2004) (Fig 1). Using the TpsRewl program (Rohlf 2007), consensus configurations were calculated from the original coordinates of each specimen by orthogonal least-squares superimposition, resulting in a reference configuration (consensus) (Monteiro \& Reis 1999). Average Mahalanobis distances were used in cluster analysis for construction of a UPGMA dendrogram. Multivariate analyses, plots and dendrograms were made using the STATISTICA version 7.0 software.

TABLE 2. Parasitoid samples used for the morphometric analysis.

\begin{tabular}{lllllll}
\hline & \multicolumn{2}{c}{ Opius bellus } & \multicolumn{3}{c}{ Opius sp. } \\
\cline { 2 - 7 } Collection sites & $\mathrm{F}$ & $\mathrm{M}$ & Codes & $\mathrm{F}$ & $\mathrm{M}$ & Codes \\
\hline Amazonas (AM) & 20 & 20 & OBAM & 20 & 20 & OPBAM \\
Amapá (AP) & 20 & 19 & OBAP & 20 & 18 & OPBAP \\
Rio Grande do Norte (RN) & 20 & 8 & OBRN & 10 & 6 & OPBRN \\
Total & 60 & 47 & & 50 & 44 & \\
\hline
\end{tabular}

Opius bellus (OB) and Opius sp. (OPB) populations from Amazonas (OBAM, OPBAM), Amapá (OBAP, OPBAP) and Rio Grande do Norte (OBRN, OPBRN).

Molecular analysis. Opius bellus and Opius sp. specimens from all Brazilian regions, northern (states of Amazonas and Amapá), northeastern (state of Rio Grande do Norte), southeastern (state of Rio de Janeiro), central (state of Tocantins) and southern (states of Santa Catarina and Rio Grande do Sul) were analyzed and illustrated using a Canon PC1099 digital camera coupled to a Zeiss Stemi 2000-C stereomicroscope. Specimens were separated based on color variation of the posterior tibiae and antenna apices into the following morphotypes: (A) yellowish tibiae and antennae, (B) yellowish tibiae/dark-brown antennae, (C) dark-brown tibiae/yellowish antennae and (D) dark-brown tibiae and antennae (Fig 2).

Genomic DNA was extracted from the abdomen of each specimen using the protocol from Aljanabi \& Martinez (1997). The abdomen was homogenized in $400 \mu \mathrm{L}$ sodium chloride tris-EDTA (TE) buffer (10 mM Tris$\mathrm{HCl} \mathrm{pH} \mathrm{8.0;} 2$ mM EDTA pH 8.0; $400 \mathrm{mM} \mathrm{NaCl}$ ) containing $40 \mu \mathrm{L}$ SDS (20\%) and $8 \mu \mathrm{L}$ of $20 \mathrm{mg} / \mathrm{mL}$ proteinase$\mathrm{K}$, and the samples were incubated at $55^{\circ} \mathrm{C}$ for $1 \mathrm{~h}$. Contaminants were removed after adding $300 \mu \mathrm{L} 6 \mathrm{M} \mathrm{NaCl}$, vortexing $(30 \mathrm{~s})$ and centrifuging $(14,000 \mathrm{~g} \mathrm{x} 25 \mathrm{~min})$. The supernatant was collected, and the DNA was precipitated by adding 1 volume of absolute cold ethanol, followed by incubation at $-20^{\circ} \mathrm{C}$ for $1 \mathrm{~h}$ and centrifugation $\left(14,000 \mathrm{~g} \times 20 \mathrm{~min} \times 4^{\circ} \mathrm{C}\right)$. The resulting DNA pellet was washed in successive absolute ethanol baths, dried at room temperature, resuspended in autoclaved Milli-Q water and stored at $-20^{\circ} \mathrm{C}$. 




FIGURE 1. Landmarks on fore wing of Opius bellus. 1. base of vein costal; 2. intersection of the parastigma, 1RS and wing margin; 3. intersection of the end of stigma and R1a; 4. intersection of the radial sector 3RSb and wing margin; 5. intersection of vein $3 \mathrm{M}$ and wing margin; 6 . intersection of vein $3 \mathrm{CU}$ and wing margin; 7. intersection of vein 3-1 $\mathrm{A}$ and wing margin; 8 . intersection of the veins $2 \mathrm{CUa}$ and $3 \mathrm{CU}$; 9. intersection of the veins 1-1A, 1 cu-a and 2-1A; 10. intersection of veins $1-1 \mathrm{~A}$ and base of wing; 11. intersection of the veins $\mathrm{M}+\mathrm{CU}, 1 \mathrm{M}$ and $1 \mathrm{CU} ; 12$. intersection of veins $\mathrm{M}+\mathrm{CU}, 1 \mathrm{cu}-\mathrm{a}$ and $1 \mathrm{CU} ; 13$. intersection of veins $2 \mathrm{CUa}, 1 \mathrm{CU}$ and $1 \mathrm{~m}-\mathrm{cu} ; 14$. intersection of veins $2 \mathrm{M}, \mathrm{r}-\mathrm{m}$ and $3 \mathrm{M} ; 15$. intersection of veins (RS+M)b, 2RS and $2 \mathrm{M} ; 16$. intersection of veins $(\mathrm{RS}+\mathrm{M}) \mathrm{a},(\mathrm{RS}+\mathrm{M}) \mathrm{b}$ and $1 \mathrm{~m}-\mathrm{cu} ; 17$. intersection of veins $1 \mathrm{M}$, $(\mathrm{RS}+\mathrm{M}) \mathrm{a}$ and $1 \mathrm{RS} ; 18$. intersection of veins 3RSa, 3RSb and $r-m ; 19$. intersection of veins 3RSa, $r$ and 2RS; 20. intersection of vein $r$ and base of stigma (venational terminology according to Sharkey \& Wharton 1997).
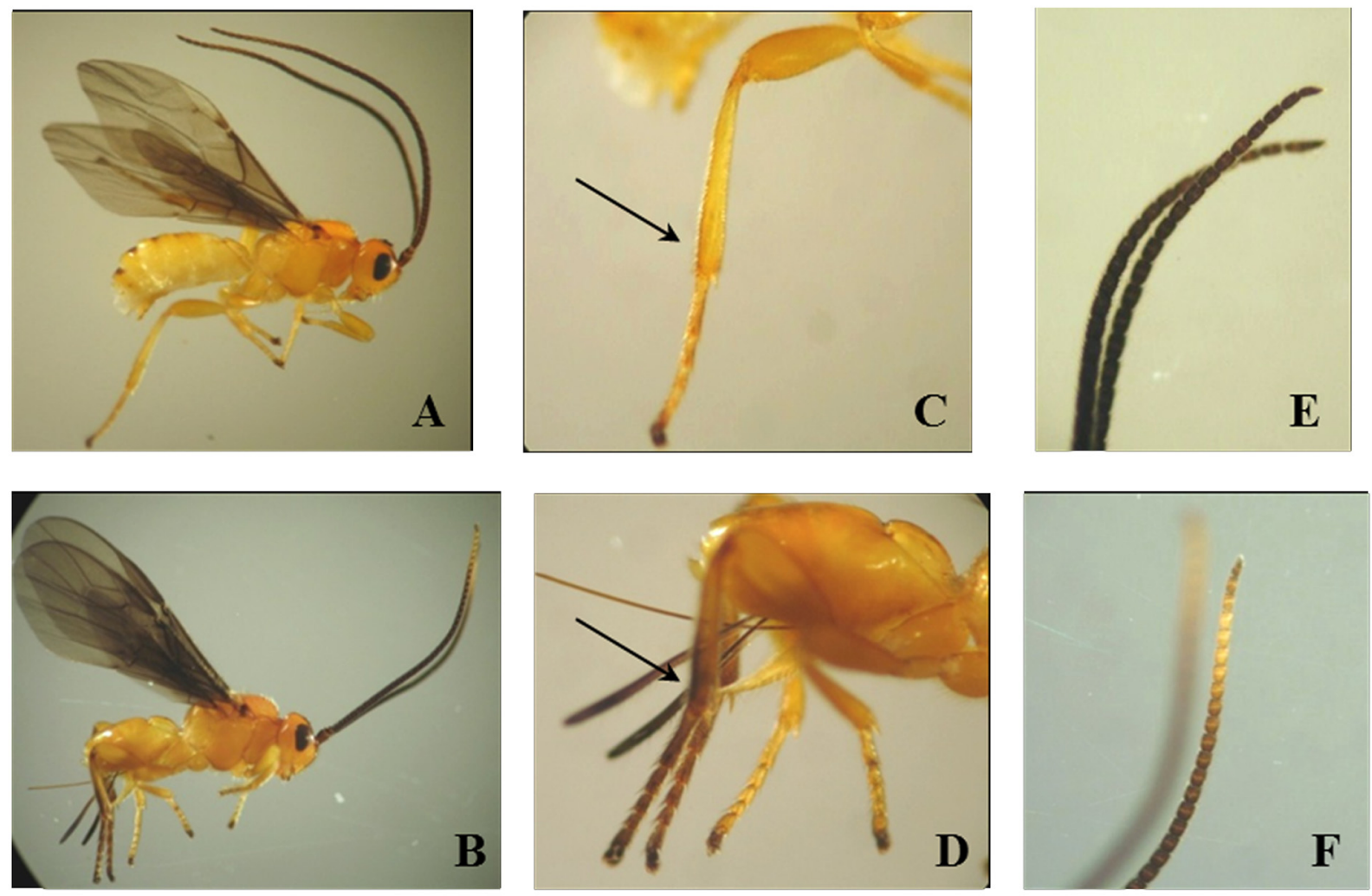

FIGURE 2. A. Opius sp.; B. Opius bellus.; C-F. chromatic variations: C. hind tibia yellowish; D. hind tibia dark-brown; E. antenna apice dark-brown; F. antenna apice yellowish (figures are not at same scale). 
DNA samples were used to amplify the "Internal Transcribed Spacer" (ITS2) region of nuclear rDNA and the expansion segment (D2) of the 28S rDNA secondary structure. Amplification of these products was performed using the set of primers $5.8 \mathrm{~S}$ (5' G T G A A T T C T G T G A A C T G C A G G A C A C A T G A A C 3') and 28S (5' A T GCT A A A T T TA GGGGGTA 3') (Porter \& Collins 1991) for ITS2, and F3665 (5'AGAGAGAGTTCAAGAGTACGTG3') and R4047 (5'TTGGTCCGTGTTTCAAGACGGG3') for 28S D2 (Belshaw \& Quick 1997). Amplification reactions were performed in a total volume of $25 \mu \mathrm{L}$, containing $1.0 \mu \mathrm{L}$ gDNA, $1 \times$ PCR buffer, $1.5 \mathrm{mM} \mathrm{MgCl}_{2}, 200 \mu \mathrm{M}$ of each dNTP, $0.32 \mu \mathrm{M}$ of each primer and 0.25 $\mathrm{U}$ of Taq polymerase (Promega). The amplification conditions for ITS2 were $94^{\circ} \mathrm{C}$ for $2 \mathrm{~min}(1 \mathrm{x})$; followed by $94^{\circ} \mathrm{C}$ for $30 \mathrm{~s}, 49^{\circ} \mathrm{C}$ for $30 \mathrm{~s}$ and $72^{\circ} \mathrm{C}$ for $1 \mathrm{~min}(35 \mathrm{x})$; and $72^{\circ} \mathrm{C}$ for $20 \mathrm{~min}(1 \mathrm{x})$. PCR conditions for the $28 \mathrm{~S}$ D2 fragment were $93^{\circ} \mathrm{C}$ for $3 \mathrm{~min}(1 \mathrm{x}) ; 98^{\circ} \mathrm{C}$ for $15 \mathrm{~s}, 48^{\circ} \mathrm{C}$ for $30 \mathrm{~s}$ and $72^{\circ} \mathrm{C}$ for $40 \mathrm{~s}(35 \mathrm{x})$; and $72^{\circ} \mathrm{C}$ for $3 \mathrm{~min}(1 \mathrm{x})$. Amplification products were run on a $1.5 \%$ agarose gel containing $0.5 \mu \mathrm{g} / \mathrm{mL}$ ethidium bromide for DNA staining, in tris-acetate-EDTA (TAE) at $5 \mathrm{~V} / \mathrm{cm}$. The gel was visualized and images were captured and digitized on a DNR Image Capturing System.

All PCR products were purified using the QIAquick PCR Purification Kit (Qiagen $囚$ ) following the manufacturer's instructions, and directly submitted for bidirectional sequencing. Otherwise, PCR products were cloned by insertion into the pGEN-T Easy Vector System I (Promega) vector and used for the transformation of competent Escherichia coli C2992 NEB5aF' (BIOLABS) cells, following the manufacturer's instructions for amplification and subsequent sequencing. Samples were bi-directionally sequenced at the Centro de Estudos do Genoma Humano (CEGH-USP) (http://genoma.ib.usp.br/servicos/sequenciamento.php) using the MegaBACE 1000 protocol and DYEnamic ET Dye Terminator Kit (with Thermo Sequenase ${ }^{\mathrm{TM}}$ II DNA Polymerase). All of the resulting sequences were analyzed and edited using the BioEdit software (http://www.mbio.ncsu.edu/BioEdit/ BioEdit.html).

Amplified ITS2 and 28S D2 rDNA sequences were first aligned using Clustal W software. The resulting sequences were also compared to sequences deposited at the National Center for Biotechnology Information (NCBI) (http://www.ncbi. nlm.nih.gov/) using the Blastn search algorithm. Sequences for the 28S D2 region of the O. bellus and Opius sp. specimens were aligned to O. basirufus Fischer (accession number Z93649.1), O. bellus Gahan (Z93650.1), O. cingulatus Wesmael (Z93651.1), O. dissitus Muesebeck (Z93652.1), O. exiguus Wesmael (Z93653.1), O. fuscipennis Wesmael (Z93654.1) and O. singularis Wesmael (as O. spretus Haliday) Haliday (Z93655.1).

Alignments were performed using the ClustalW software with a gap open penalty of 13.0 and gap extension penalty of 7.6. The Tamura-Nei method for distance estimation was used to reconstruct the cluster tree (Tamura \& Nei 1993). Correction for differences in rates regarding the number and types of transitions and transversions was not necessary. Aligned sequences were analyzed using the neighbor joining (NJ) method with 1,000 repetitions for bootstrap analysis. All analyses were performed using the statistical package MEGA 4.0 (Tamura et al. 2007). All sequences obtained for ITS2 and 28S D2 were deposited at the GenBank database under accession numbers FJ560504 to FJ560533.

\section{Results}

\section{Geometric morphometry}

Geometric morphometry generated 36 measurements of relative deformations $(\mathrm{k}=2 \mathrm{n}-4)$, where $k$ represented the total number of relative deformations and $n$ the number of anatomical landmarks. Analysis of canonical variables in male and female of O. bellus and of Opius sp. from the states of Amazonas, Amapá and Rio Grande do Norte showed that the canonical axes were statistically significant, according to the values of Wilk's lambda $(p<0.0001)$, Pillai's trace $(p<0.0001)$, Hotelling-Lawley trace $(p<0.0001)$ and Roy's greatest root $(p<0.0001)$. The first two canonical axes explained $55.1 \%$ and $32.1 \%$ of the variance in the data, respectively. The scatterplot containing the projections of the morphotype populations in the three states showed three groupings. The first and the second groups were created from the total superimposition of $O$. bellus and Opius sp. from Amazonas and Amapá, respectively, and the third group was created by the partial superimposition of $O$. bellus and Opius sp. from Rio Grande do Norte (Fig 3). In the Mahalanobis distance matrix, O. bellus and Opius sp. from Amazonas and Amapá 
were more similar than the specimens from Rio Grande do Norte (Table 4). However, it was clear that the O. bellus and Opius sp. specimens were morphologically similar in all three states (Fig 4). The centroid size showed that the wing size of $O$. bellus and Opius sp. from Rio Grande do Norte, Amazonas and Amapá was similar (Fig 6).
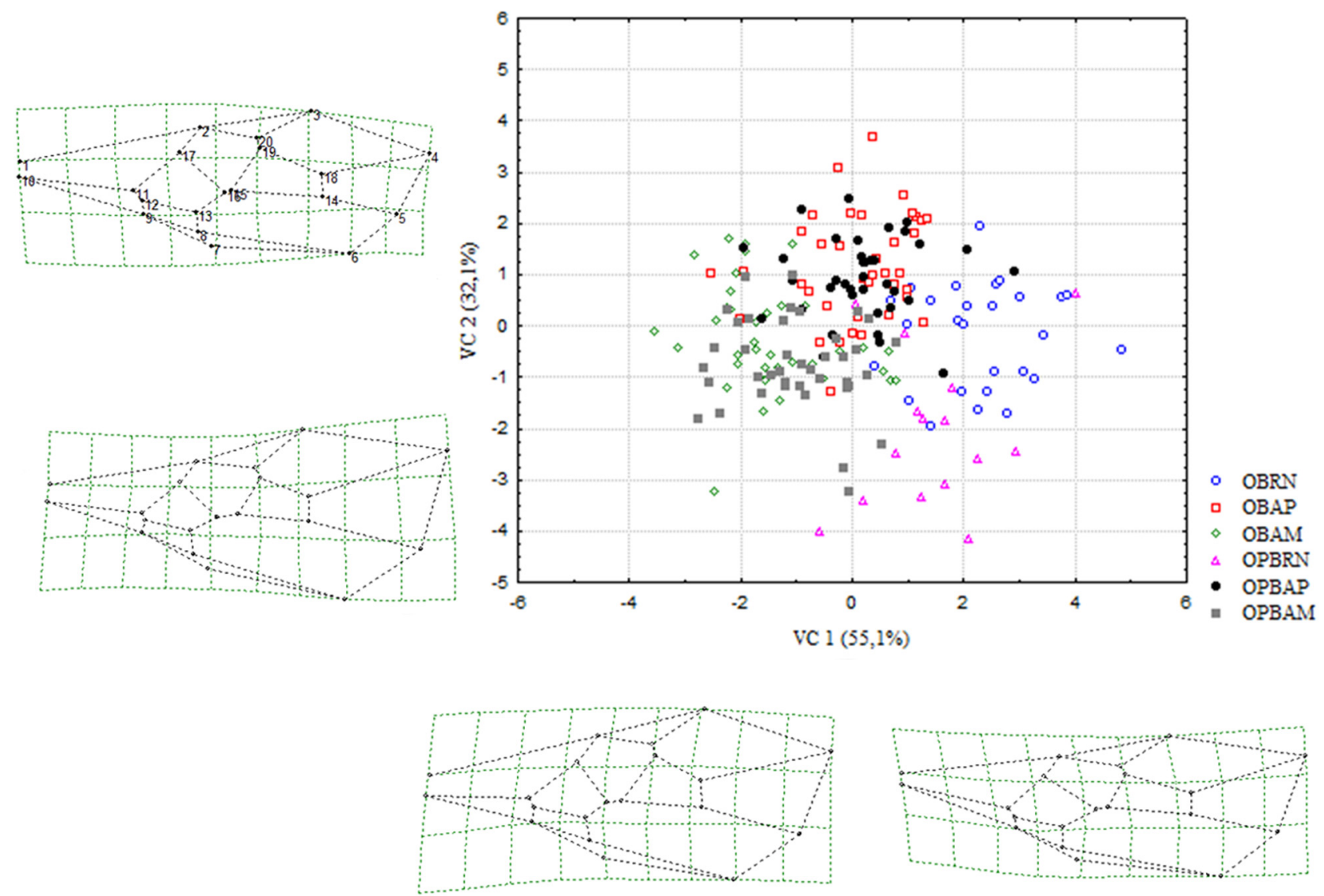

FIGURE 3. Dispersion graphic of Opius bellus and Opius sp. males and females from Amazonas, Amapá and Rio Grande do Norte in the bidimensional space of canonical variables VC1 and VC2. The deformations diagrams indicate the presumable wing conformations for individuals in the superior and inferior ends of the canonical variables. Deformation magnitudes were amplified $3 \mathrm{x}$ for visualization. $(\mathrm{OBRN}=O$. bellus from Rio Grande do Norte, $\mathrm{OBAP}=O$. bellus from Amapá, $\mathrm{OBAM}=O$. bellus from Amazonas, OPBRN = Opius sp. from Rio Grande do Norte, OPBAP = Opius sp. from Amapá, OPBAM Opius sp. from Amazonas).

\section{Molecular analysis}

Analysis of the ITS2 and 28S D2 markers revealed size and sequence differences for O. bellus and Opius sp., especially for the ITS2 fragment. ITS2 fragment size ranged from 658 to $669 \mathrm{bp}$, and sequence analysis of all individuals in the samples allowed the verification of intrapopulation and interpopulation variability in nucleotide sequence composition. However, although differences were observed, ITS2 sequence composition was very similar, and the regions with the most frequent differences occurred indistinctively in both morphospecies (Table 3 and Online Supplementary Material). The 28S D2 marker had a single fragment size of $428 \mathrm{bp}$, displaying high nucleotide similarity between $O$. bellus and Opius sp. Alignment of the sequences to other species in the same genus available from NCBI revealed high divergence of the sequences we generated with those of other Opius species, with the exception of $O$. bellus (accession number Z93650.1) (Online Supplementary Material). The cladogram for the molecular marker (28S D2) revealed two groups, one of which contained the specimens from this study, O. bellus and Opius sp., in addition to O. bellus (accession number Z93650.1), and another group containing the remaining species in the genus available from NCBI. Although the support for the branches formed between the Opius (NCBI) species demonstrated bootstrap values below $50 \%$, the clade formed by grouping the analyzed morphotypes and $O$. bellus (accession number Z93650.1) received a support of 100\% (Fig 5). 
TABLE 3. Sample identification, molecular marker used, fragment size, and GenBank access number for each parasitoid specimens analyzed.

\begin{tabular}{lllll}
\hline Codes $^{*}$ & Parasitoids & Markers & Size & GenBank (access) \\
\hline 1AAMM1 & Opius sp. & ITS2/28SD2 & $661 \mathrm{pb} / 428 \mathrm{pb}$ & FJ560519 - FJ560504 \\
2BAMM2 & Opius sp. & ITS2/28SD2 & $661 \mathrm{pb} / 428 \mathrm{pb}$ & FJ560520 - FJ560505 \\
3CAMM3 & O. bellus & ITS2/28SD2 & $666 \mathrm{pb} / 428 \mathrm{pb}$ & FJ560521 - FJ560506 \\
4AAMF1 & Opius $\mathrm{sp}$ & ITS2/28SD2 & $662 \mathrm{pb} / 428 \mathrm{pb}$ & FJ560522 - FJ560507 \\
5DAMF2 & O. bellus & ITS2/28SD2 & $661 \mathrm{pb} / 428 \mathrm{pb}$ & FJ560523 - FJ560508 \\
6AAPM1 & Opius sp. & ITS2/28SD2 & $665 \mathrm{pb} / 428 \mathrm{pb}$ & FJ560524 - FJ560509 \\
7AAPF1 & Opius sp. & ITS2/28SD2 & $659 \mathrm{pb} / 428 \mathrm{pb}$ & FJ560525 - FJ560510 \\
8ARNF1 & Opius sp. & ITS2/28SD2 & $659 \mathrm{pb/428pb}$ & FJ560526 - FJ560511 \\
9DRNF2 & O. bellus & ITS2/28SD2 & $663 \mathrm{pb} / 428 \mathrm{pb}$ & FJ560527 - FJ560512 \\
10DRJF1 & O. bellus & ITS2/28SD2 & $663 \mathrm{pb/428pb}$ & FJ560528 - FJ560513 \\
11DTOF1 & O. bellus & ITS2/28SD2 & $658 \mathrm{pb/428pb}$ & FJ560529 - FJ560514 \\
12DRSF1 & O. bellus & ITS2/28SD2 & $663 \mathrm{pb/428pb}$ & FJ560530 - FJ560515 \\
13CRSF2 & Opius sp. & ITS2/28SD2 & $669 \mathrm{pb/428pb}$ & FJ560531 - FJ560516 \\
14DSCF1 & O. bellus & ITS2/28SD2 & $659 \mathrm{pb/428pb}$ & FJ560532 - FJ560517 \\
15CSCF2 & O. bellus & ITS2/28SD2 & $666 \mathrm{pb/428pb}$ & FJ560533 - FJ560518 \\
\hline
\end{tabular}

*The first letter represents the color pattern of the tibia and antenna (A-yellow tibia and antenna, B-yellow tibia / dark-brown antenna, C-dark-brown tibia and antenna, D-dark-brown tibia /yellow antenna), the second and third letters the state from were samples were collected (AP-Amapá, AM-Amazonas, RN-Rio Grande do Norte, RS—Rio Grande do Sul, SC-Santa Catarina, TO-Tocantins), the fourth letter the sex of the specimen, and the last number refers to the specimen analyzed.

The observed genetic distance between the various morphotypes by comparative analysis of the $28 \mathrm{~S}$ D2 sequences we generated, together with those available from NCBI, supports the cladogram results showing high similarity between the morphotypes with different posterior tibia and antenna coloration ( $99 \%$ to $100 \%$ ), regardless of their geographic origin (Fig 5, Online Supplementary Material). The samples analyzed here exhibited 99\% similarity with the $O$. bellus sequence (accession number Z93650.1) available from NCBI (99\%), but had less than $90 \%$ similarity with the other species in the genus, confirming that they have diverged (Online Supplementary Material).

TABLE 4. Mahalanobis distances of Opius bellus (OB) and Opius sp. (OPB) populations from Amazonas (OBAM, OPBAM), Amapá (OBAP, OPBAP) and Rio Grande do Norte (OBRN, OPBRN) based on wing shape components.

\begin{tabular}{lllllll}
\hline Parasitoids & OBRN & OBAP & OBAM & OPBRN & OPBAP & OPBAM \\
\hline OBRN & 0.0 & & & & & \\
OBAP & 7.9 & 0.0 & & & & \\
OBAM & 14.3 & 5.0 & 0.0 & & & \\
OPBRN & 7.7 & 12.8 & 13.4 & 0.0 & 0.0 & \\
OPBAP & 6.8 & 0.5 & 4.7 & 11.5 & 4.7 & 0.0 \\
OPBAM & 11.9 & 5.3 & 1.2 & 9.6 & \\
\hline
\end{tabular}

\section{Discussion}

The consistency between the results of the morphometric and molecular analyses highlights the similarity between $O$. bellus and Opius sp. Moreover, multivariate morphometry showed similarity between the morphological variables of $O$. bellus and Opius sp. wings, and the plot of the canonical variables revealed clear separation of the 
morphotypes from each state (Amazonas, Amapá and Rio Grande do Norte) in the space of the first two canonical variables, which accounted for the majority of the significant variance $(87.2 \%)$. The resulting dendrogram, calculated based on the Mahalanobis distance, was well correlated with the tree constructed from the molecular analysis, where the genetic similarity of the specimens with different tibia coloration and geographic origins was clearly observed (Figs 4 and 5).



FIGURE 4. Dendrogram of populations of Opius bellus and Opius sp. from Rio Grande do Norte (OBRN, OPBRN), Amazonas (OBAM, OPBAM) and Amapá (OBAP, OPBAP) generated by cluster analysis (UPGMA) from Mahalanobis distances presented in Table 4.

Although genetic similarity observed among morphotypes, the morphometric analysis showed a small divergence between the specimens from Rio Grande do Norte and those from Amazonas and Amapá. The habitat where these species originate from can strongly influence the individual variability because interactions with biotic, such as host larvae (Villemant et al. 2007), and abiotic factors (temperature, humidity, pluvial precipitation), as well as the unique features of each environment can directly affect these populations (Futuyma 1992).

Such an environmental difference was observed in the wing morphology of O. bellus and Opius sp. specimens; in particular, the wing size of males and females in the morphotypes from each state, represented by the centroid size, were generally similar, i.e., $O$. bellus and Opius sp. had the same wing size, but the proportions were different from the three states (Fig 6). In the deformation diagrams, O. bellus and Opius sp. from Amazonas, located at the lower end of $\mathrm{VC} 1$ (negative score), had wings that were slightly wider in the dorsoventral region and shorter than the population from Rio Grande do Norte, which is located at the upper end of VC1 (positive score). The morphotypes from Amapá demonstrated longer wings, with strong compression in the medial-apical region compared to the base and were located at the upper end of the VC2 axis (positive score) (Fig 3). Because of the homology of the landmarks found in the analyzed structure and the use of cartesian coordinates, minimal morphological variations could be detected, as is common in geometric morphometry, thereby providing a powerful tool for studies on systematics (Monteiro \& Reis 1999; Baylac et al. 2003; Villemant et al. 2007).

In the genetic analyses, the ITS2 marker raised doubts about the identity of Opius sp. due to the large amount of intra and interspecific variability in the sequences. This molecular marker is widely used to differentiate species (Hillis \& Dixon 1991; Ciociola et al. 2001; Gallego \& Galián 2001; Wilkerson et al. 2004). However, there are cases where a species exhibits interindividual genomic variation for ITS2 sequence and length (Onyabe \& Conn 1999), which may (Rich et al. 1997) or may not (Alvarez \& Hoy 2002) result in erroneous phylogenies. In this study, the intraspecific variability found in the ITS2 region of the morphospecies analyzed was as high as the variability found between individuals of distinct morphospecies. Thus, regardless of the identified differences, the 
sequences were very similar, and the regions where the variations were most frequent occurred indistinctively between morphospecies.

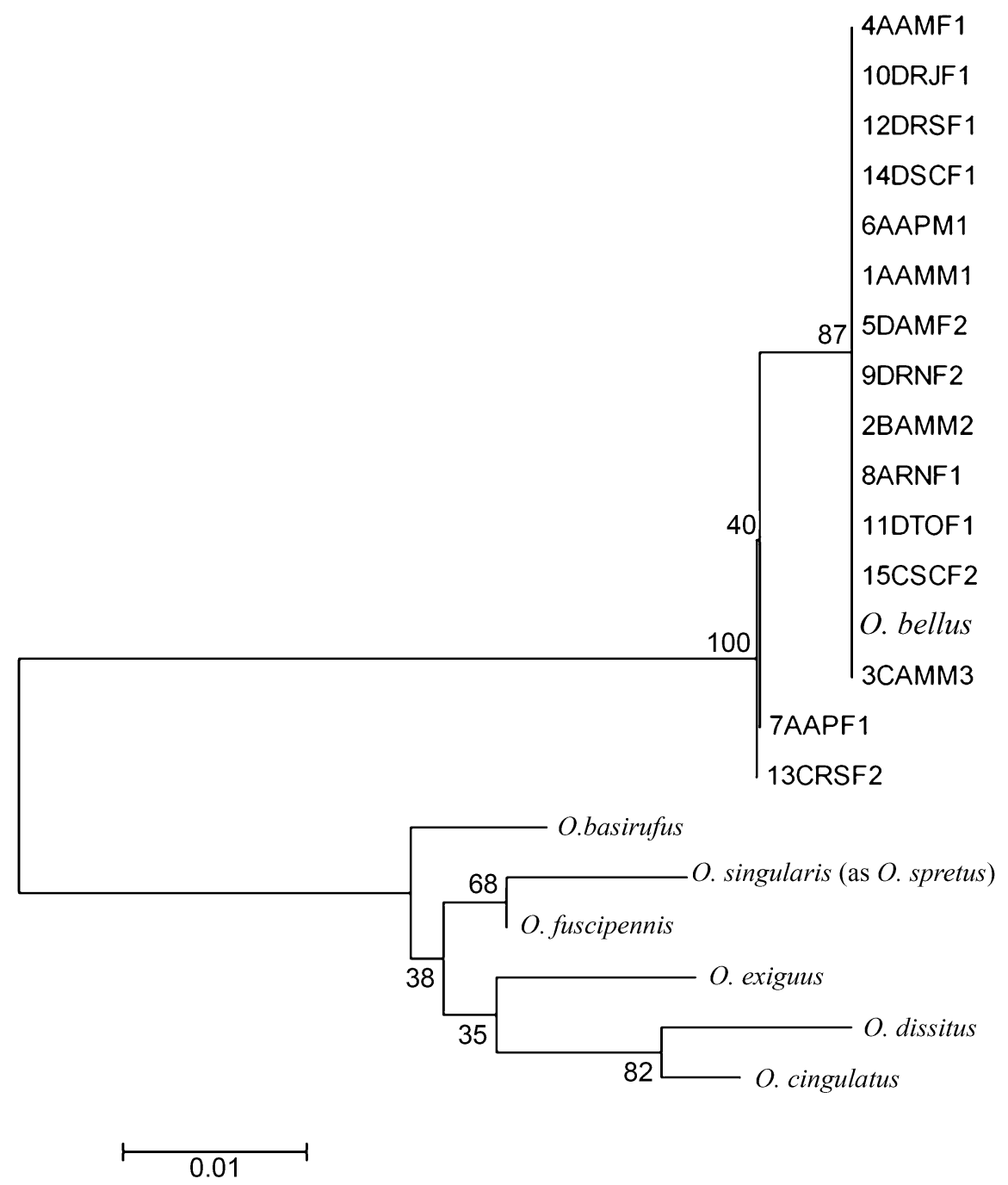

FIGURE 5. Neighbour-Joining (NJ) linearized trees produced from the alignment of nucleotides of the $28 \mathrm{~S}$ rDNA D2 region from Opius bellus and Opius sp. specimens from populations collected in several Brazilian states and other Opius species obtained from the GenBank. Numbers in the branches indicate

In contrast, the 28S D2 marker clearly defined the taxonomic identity of Opius sp. The $28 \mathrm{~S}$ marker has been widely used in Hymenoptera to distinguish species by the presence of a number of nuclear elements and 13 expansion segments, especially the highly conserved D2 and D3 segments (Heraty et al. 2004; Gillespie et al. 2005). The D2 segment of the $28 \mathrm{~S}$ has previously been used to recover morphologically congruent relationships between Opiinae and Alysiinae (Belshaw \& Quick 1997), supporting the monophyletic nature of all of the members of the family Braconidae (Shi et al. 2005). In addition, this segment was used in the first phylogenetic reconstruction of the superfamily Ichneumonoidea (Belshaw et al. 1998).

In this study, the 28S D2 marker was important for clarifying the identity of $O$. bellus, as this species exhibits color variation in Brazil. Ovruski et al. (2000) considered that $O$. bellus represents a species complex in Brazil. However, the 28S rDNA D2 marker, regardless of the antenna and tibia color variation or geographic origin, demonstrated the similarity between $O$. bellus and Opius sp., as the size of their sequences (428 bp) and nucleotide similarity were practically identical. Thus, chromatic variations appear to be plastic phenotypic responses caused by environmental conditions.

Together, these morphometric and molecular analyses showed that $O$. bellus and Opius sp. specimens are conspecific and represent intraspecific variations of Opius bellus. 

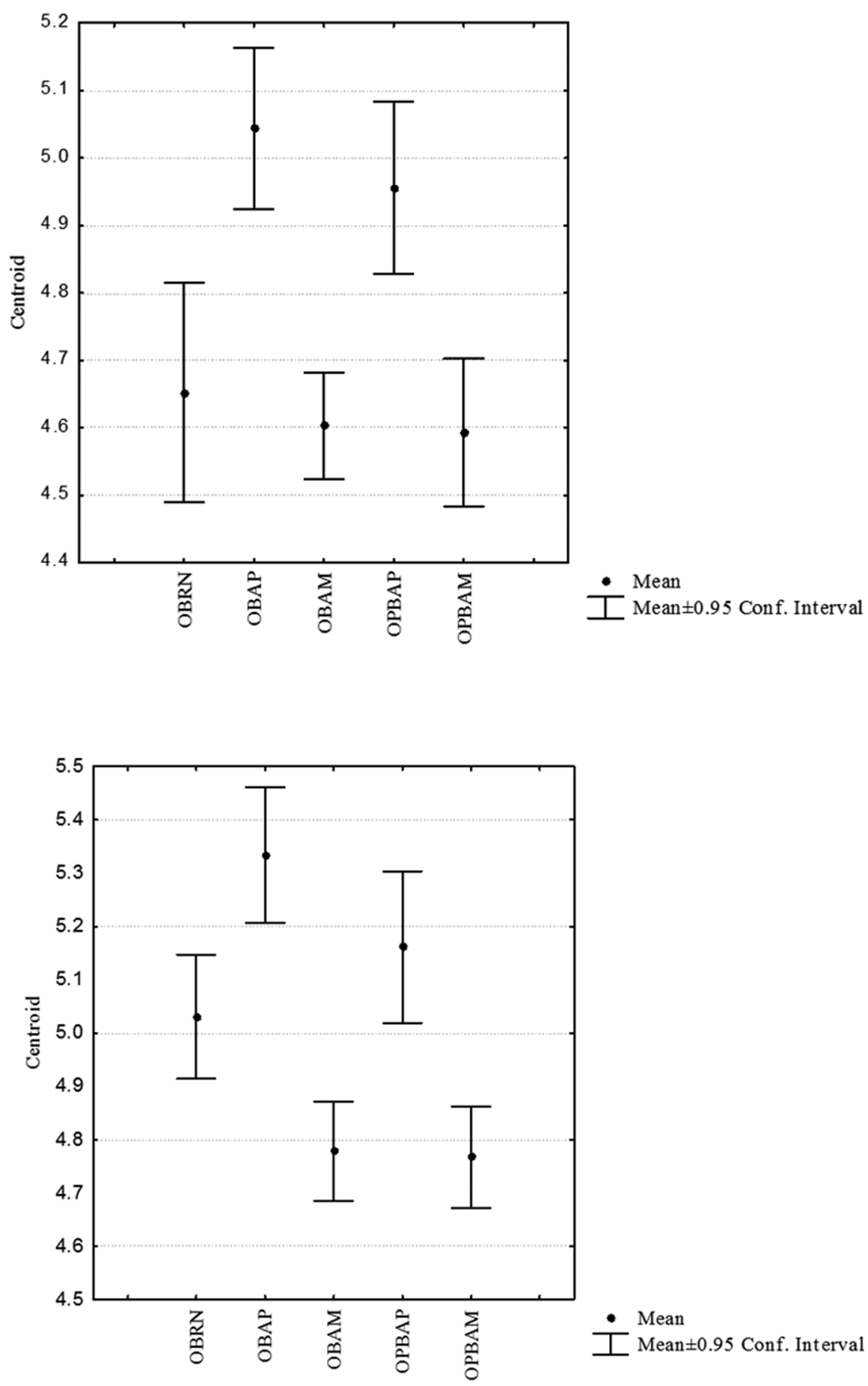

FIGURE 6. Centroid size of male (top) and female (bottom) wings of Opius bellus and Opius sp. from Amazonas, Amapá and Rio Grande do Norte.

\section{Acknowledgements}

We thank Dr. Sérgio Furtado dos Reis, Dr. Rute Garcia Beatriz Clemente and Dr. Ivan Perez of the Parasitology Laboratory of the State University of Campinas (Universidade Estadual de Campinas - Unicamp) for help with the geometric morphometry analysis and all the researchers who sent samples for this study. We also thank the Coordenação de Aperfeiçoamento de Ensino Superior (CAPES) for a Doctorate fellowship awarded to the first author. 


\section{References}

Aljanabi, S.M. \& Martinez, I. (1997) Universal and rapid salt-extraction of high quality genomic DNA for PCR-based techniques. Nucleic Acids Research, 25 (22), 4692-4693. http://dx.doi.org/10.1093/nar/25.22.4692

Alvarez, J.M. \& Hoy, M. (2002) Evaluation of the Ribosomal ITS2 DNA sequences in separating closely related populations of the parasitoid Ageniaspis (Hymenoptera: Encyrtidae). Annals of the Entomological Society American, 95 (2) $250-256$. http://dx.doi.org/10.1603/0013-8746(2002)095[0250:eotrid]2.0.co;2

Baylac, M., Villemant, C. \& Simbolotti, G. (2003) Combining geometric morphometrics with pattern recognition for the investigation of species complexes. Biological Journal of the Linnean Society, 80, 89-98. http://dx.doi.org/10.1046/j.1095-8312.2003.00221.x

Belshaw, R. \& Quicke, D.L.J. (1997) A molecular phylogeny of the Aphidiinae (Hymenoptera: Braconidae). Molecular Phylogenetics and Evolution, 7, 281-293. http://dx.doi.org/10.1006/mpev.1996.0400

Belshaw, R., Fitton, M., Herniou, E., Gimeno, C. \& Quicke, D.L.J. (1998) A phylogenetic reconstruction of the Ichneumonoidea (Hymenoptera) based on the D2 variable region of 28S ribosomal RNA. Systematic Entomology, 23, 109-123. http://dx.doi.org/10.1046/j.1365-3113.1998.00046.x

Ciociola Jr., A.I., Querino, R.B., Zucchi, R.A. \& Stouthamer, R. (2001) Molecular tool for identification of closely related species of Trichogramma (Hymenoptera: Trichogrammatidae) T. rojasi Nagajara \& Nagarkatti and T. lasallei Pinto. Neotropical Entomology, 30 (4), 575-578. http://dx.doi.org/10.1590/s1519-566x2001000400010

Futuyma, D.J. (1992) Biologia Evolutiva. Editora Funpec, Ribeirão Preto, 631 pp.

Gallego, D. \& Galián, J. (2001) The internal transcribed spacers (ITS1 and ITS2) of the rDNA differentiates the bark beetles forest pests Tomicus destruens and T. piniperda. Insect Molecular Biology, 10 (5), 415-420. http://dx.doi.org/10.1046/j.0962-1075.2001.00279.x

Gillespie, J.J., Munro, J.B., Heraty, J.M., Yoder, M.J., Owen, A.K. \& Carmichael, A.E. (2005) A Secondary structural model of the 28S rRNA expansion segments D2 and D3 for Chalcidoid wasps (Hymenoptera: Chalcidoidea). Molecular Biology and Evolution, 22 (7) 1593-1608.

Heraty, J.M., Hawks, D., Kostecki, J.S. \& Carmichael, A. (2004) A. Phylogeny and behavior of the Gollumiellinae, a new subfamily of the ant parasitic Eucharitidae (Hymenoptera: Chalcidoidea). Systematic Entomology, 29 (4) 544-559. http://dx.doi.org/10.1111/j.0307-6970.2004.00267.x

Hillis, D.M. \& Dixon, M.T. (1991) Ribosomal DNA: molecular evolution and phylogenetic inference. The Quartely Review of Biology, 66, 411-453.

Leonel Júnior, F.L., Zucchi, R.A. \& Canal Daza, N.A. (1996) Parasitismo de moscas-das-frutas (Diptera: Tephritidae) por Braconidae (Hymenoptera) em duas localidades do Estado de São Paulo. Anais da Sociedade Entomológica do Brasil, Jaboticabal, 25 (2), 199-206.

Monteiro, L.R. \& Reis, S.F. (1999) Princípios de Morfometria Geométrica. Holos Editora, Ribeirão Preto, 188 pp.

Onyabe, D.Y. \& Conn, J.E. (1999) Intragenomic heterogeneity of a ribosomal DNA spacer (ITS2) varies regionally in the Neotropical malaria vector Anopheles nuneztovari (Diptera: Culicidae), Insecta Molecular Biology, 8 (4), $435-442$. http://dx.doi.org/10.1046/j.1365-2583.1999.00134.x

Ovruski, S., Aluja, M., Sivinski, J. \& Wharton, R. (2000) Hymenopteran parasitoids on fruit-infesting Tephritidae (Diptera) in Latin America and the Southern United States: Diversity, distribution, taxonomic status and their use in fruit fly biological control. Integrated Pest Management Reviews, 5 (2), 81-107.

Porter, C.H \& Collins, F.H (1991) Species-diagnostic differences in a ribosomal DNA internal transcribe spacer from the sibling species Anopheles freeborni and Anopheles hermsi (Diptera: Culicidae). The American Journal of Tropical Medicine and Hygiene, 45 (2), 271-279.

Rohlf, F.J. (2004) Program tpsDig, version 1.40. Stony brook, State University of New York, Department of Ecology and Evolution.

Rohlf, F.J. (2007) Program tpsRegr, version 1.33. Stony Brook, State University of New York, Department of Ecology and Evolution.

Rich, S.M., Rosenthal, B.M., Telford, S.R. III, Spielman, A., Hartl, D.L. \& Ayala, F.J (1997) Heterogeneity of the internal transcribed spacer (ITS-2) region within individual deer ticks, Insect Molecular Biology, 6 (2), 127-129.

Sharkey, M.J. \& Wharton, R.A. (1997) Morphology and terminology. In: Wharton, R.A., Marsh, P.M. \& Sharkey, M.J. (Eds.), Manual of the New World genera of the family Braconidae (Hymenoptera). Special Publication of the International Society of Hymenopterists, Number 1. International society of Hymenopterists, Washington D.C., pp. 19-38.

Shi, M., Chen, X.X. \& Van Achterberg, C. (2005) Phylogenetic relationships among the Braconidae (Hymenoptera: Ichneumonoidea) inferred from partial 16SrDNA, 28SrDNA D2, 18S rDNA gene sequences and morphological characters. Molecular Phylogenetics and Evolution, 37, 104-116.

Tamura, K. \& Nei, M. (1993) Estimation of the number of nucleotide substitutions in the control region of mitochondrial DNA in humans and chimpanzees. Molecular Biology and Evolution, 10 (3), 512-526. 
Tamura, K., Dudley, J., Nei, M. \& Kumar, S. (2007) MEGA 4.0: Molecular Evolutionary Genetic Analysis (MEGA) software version 4.0. Molecular Biology and Evolution, 24 (8), 1596-1599.

http://dx.doi.org/10.1093/molbev/msm092

Villemant, C., Simbolotti, G. \& Kenis, M. (2007) Discrimination of Eubazus (Hymenoptera, Braconidae) sibling species using geometric morphometrics analysis of wing venation. Systematic Entomology, 32 (4), 625-634. http://dx.doi.org/10.1111/j.1365-3113.2007.00389.x

Wharton, R.A. \& Marsh, PM. (1978) New world Opiinae (Hymenoptera: Braconidae) parasitic on Tephritidae (Diptera). Journal of the Washington Academy of Sciences, 68 (4), 147-167.

Wilkerson, R.C., Reinert, J.F. \& Li, C. (2004) Ribosomal DNA ITS2 sequences differentiate six species in the Anopheles crucians complex (Diptera: Culicidae). Journal of Medical Entomology, 41 (3), 392-401.

http://dx.doi.org/10.1603/0022-2585-41.3.392 